\title{
Editorial: The 'words' of Volume 8
}

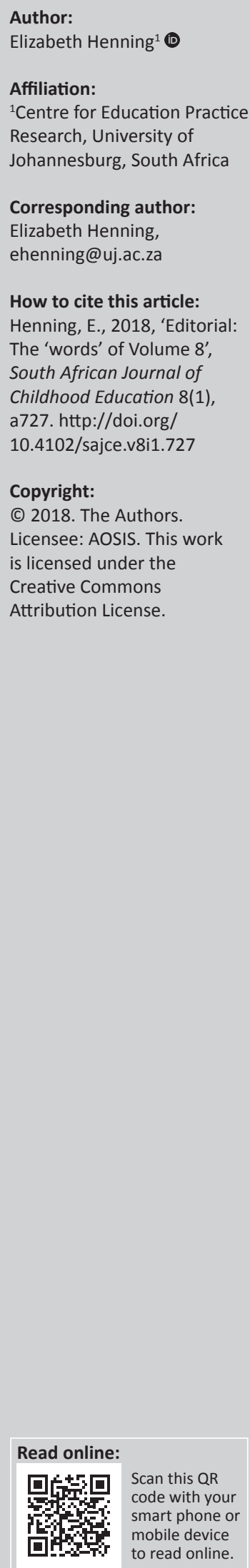

Volume 8 of the South African Journal of Childhood Education (SAJCE) reflects what researchers in the field of childhood education regard as worthwhile research topics. I used one of the 'fun' tools of our online world to see which words in the titles of the 30 published articles of this volume were the most prevalent. It was reassuring to find that teachers, learners, development, children, developmental, reading, learning and academic were some of the words used most often. The word, father, appears once in the list. I would like to see more publications about fathers and their involvement in their children's education. I think we make too little of parenthood, specifically fathers' role in bringing up children. I hope we see more research about our dads.

As a collection of words, purely as lexical items, the 'wordcloud' (Figure 1) is evidence that we, as practitioners of childhood education research, produce scholarly products that are important. I noted not only nouns but also a whole range of adjectives, verbs and adverbs. It is, however, somewhat unsettling to see that verbs are rather scant in the titles, except when they have been nominalised: teaching, learning, reading and thinking are words mostly used as nouns. I would have loved to see more verbs.

The collection of titles in this volume is contributed by authors from various fields and from different parts of the world. There is, also, a group of authors who have indicated in their communication with the editorial - and the production team - that they are first-time writers. They deserve a \#shoutout from the editor and the section editors. Thank you for your perseverance through the revisions and resubmissions. The SAJCE was founded, in the first instance, for researchers like you.

Our authors' work is recognised by the South African Department of Higher Education and Training, with a sponsorship of 50\% of handling costs ('page fees'). This generous grant has given the journal a great boost, making it possible to work with the African Online Scientific Information

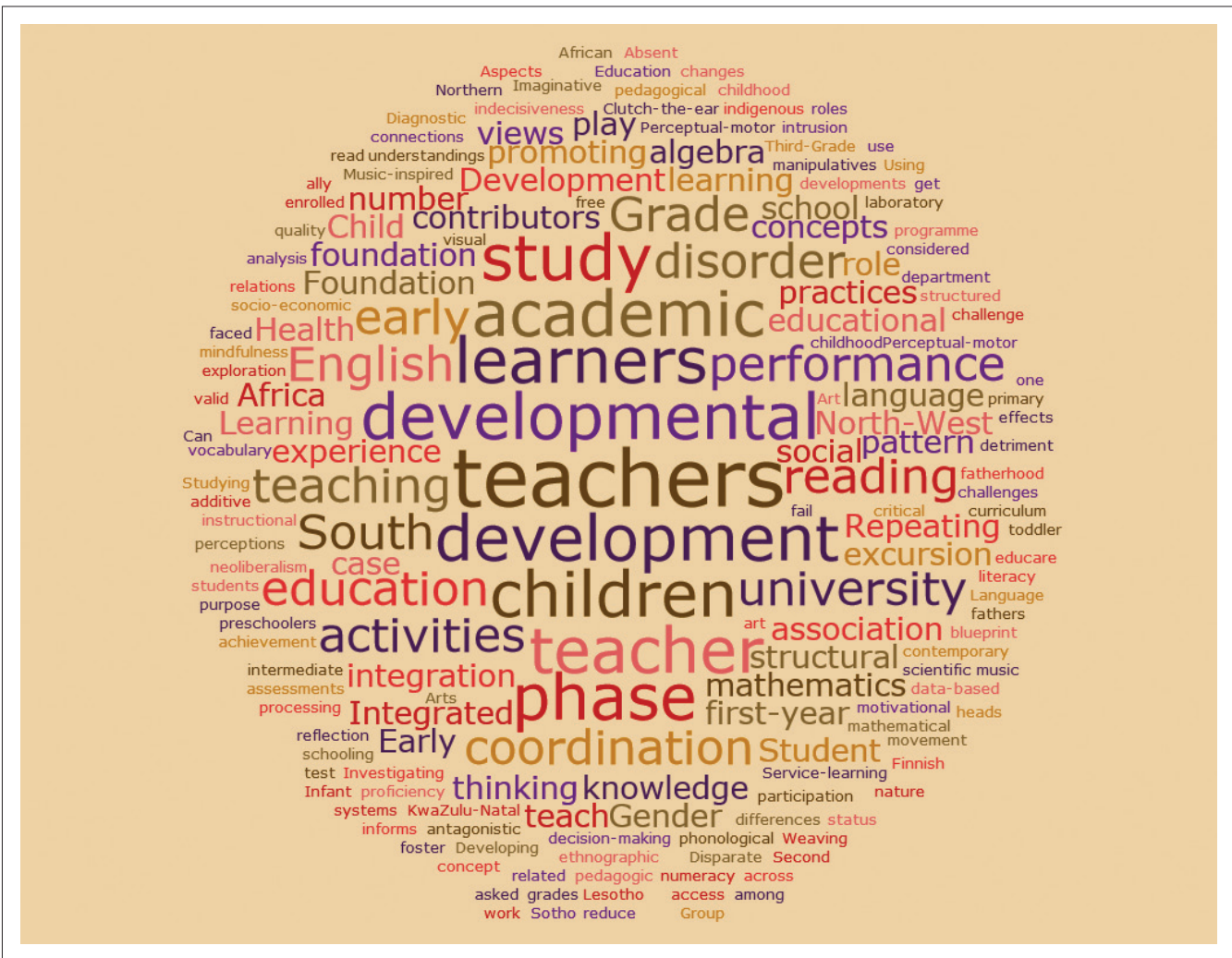

Figure 1: Wordcloud. 
Systems (AOSIS), our publisher, specifically to encourage new authors.

From 2019 we will produce only one volume, with articles published as they are finalised. Special themes will be published as 'rolling' collections, ensuring that research findings are published as soon as possible. We will follow the model of AERA Open (https://journals.sagepub.com/ home/ero).
SAJCE looks forward to submissions. We currently have 18 manuscripts in editing and 67 under review. I wish to thank the section editors, along with the AOSIS team, for their superb work during 2018.

Editorially yours

Elizabeth Henning Twitter: @Elbie.Henning 